\title{
Longitudinal Cerebral Blood Flow and Amyloid Deposition: An Emerging Pattern?
}

\author{
Jitka Sojkova ${ }^{1,2}$, Lori Beason-Held ${ }^{1}$, Yun Zhou ${ }^{2}$, Yang An ${ }^{1}$, Michael A. Kraut ${ }^{2}$, Weigo Ye $^{2}$, Luigi Ferrucci ${ }^{1}$, \\ Chester A. Mathis ${ }^{3}$, William E. Klunk ${ }^{4}$, Dean F. Wong ${ }^{2,5,6}$, and Susan M. Resnick ${ }^{1}$ \\ ${ }^{I}$ National Institute on Aging, National Institutes of Health, Bethesda, Maryland; ${ }^{2}$ Department of Radiology, Johns Hopkins University, \\ Baltimore, Maryland; ${ }^{3}$ Department of Radiology, University of Pittsburgh, Pittsburgh, Pennsylvania; ${ }^{4}$ Department of Psychiatry, \\ University of Pittsburgh, Pittsburgh, Pennsylvania; ${ }^{5}$ Department of Psychiatry, Johns Hopkins University, Baltimore, Maryland; \\ and ${ }^{6}$ Department of Environmental Health Sciences, Johns Hopkins University, Baltimore, Maryland
}

\begin{abstract}
Although cerebral amyloid deposition may precede cognitive impairment by decades, the relationship between amyloid deposition and longitudinal change in neuronal function has not, to our knowledge, been studied. The aim of this article was to determine whether individuals without dementia with high and low amyloid burden show different patterns of longitudinal regional cerebral blood flow ( $\mathrm{rCBF}$ ) changes in the years preceding measurement of amyloid deposition. Methods: Twenty-eight participants without dementia (mean age \pm SD, $82.5 \pm 4.8 \mathrm{y} ; 6$ mildly impaired) from the Baltimore Longitudinal Study of Aging underwent yearly restingstate ${ }^{15} \mathrm{O}-\mathrm{H}_{2} \mathrm{O}$ PET scans for up to $8 \mathrm{y} .{ }^{11} \mathrm{C}$-PIB images of amyloid deposition were acquired on average $10.8 \pm 0.8 \mathrm{y}$ after the first CBF scan. ${ }^{11} \mathrm{C}-\mathrm{PIB}$ distribution volume ratios of regions of interest were estimated by fitting a reference-tissue model to the measured time-activity curves. On the basis of mean cortical distribution volume ratios, participants were divided into groups with high or low ${ }^{11} \mathrm{C}-\mathrm{PIB}$ retention. Differences in longitudinal rCBF changes between high- and low- ${ }^{11} \mathrm{C}$-PIB groups were investigated by voxelbased analysis. Results: Longitudinal rCBF changes differed significantly between high- $(n=10)$ and low- $(n=18){ }^{11} \mathrm{C}-\mathrm{PIB}$ groups $(P \leq 0.001)$. Greater longitudinal decreases in rCBF in the high- ${ }^{11} \mathrm{C}-\mathrm{PIB}$ group than in the low- ${ }^{11} \mathrm{C}-\mathrm{PIB}$ group were seen in right anterior to middle cingulate, right supramarginal gyrus, left thalamus, and midbrain bilaterally. Greater increases in rCBF over time in the high- ${ }^{11} \mathrm{C}-\mathrm{PIB}$ group were found in left medial and inferior frontal gyri, right precuneus, left inferior parietal lobule, and left postcentral gyrus. Conclusion: In this group of older adults without dementia, those with high ${ }^{11} \mathrm{C}$-PIB show greater longitudinal declines in rCBF in certain areas, representing regions with greater decrements in neuronal function. Greater longitudinal increases in rCBF are also observed in those with higher amyloid load and may represent an attempt to preserve neuronal function in these regions.
\end{abstract}

Key Words: PIB; CBF; longitudinal; positron emission tomography; aging

J Nucl Med 2008; 49:1465-1471

DOI: 10.2967/jnumed.108.051946

\footnotetext{
Received Feb. 27, 2008; revision accepted May 28, 2008.

For correspondence or reprints contact: Susan M. Resnick, Laboratory of Personality and Cognition, National Institutes of Health Biomedical Center, National Institute on Aging, IRP, Suite 100, Room 04B336, 251 Bayview Blvd., Baltimore, MD 21224-6825.

E-mail: susan.resnick@nih.gov

COPYRIGHT @ 2008 by the Society of Nuclear Medicine, Inc.
}

$\mathbf{T}$ he development of in vivo amyloid imaging agents provides the opportunity to investigate prospective changes in amyloid deposition as a potential early marker of cognitive impairment and Alzheimer's disease (AD) (1). Imaging studies have shown increased amyloid deposition in patients with $\mathrm{AD}$ and in some individuals with mild cognitive impairment (MCI), a condition thought to represent a transition between normal aging and AD (2). Studies of individuals without dementia focus on the ability of ${ }^{11} \mathrm{C}$ PIB and other amyloid imaging agents to differentiate between individuals who will and who will not progress to $\mathrm{AD}(1,3-6)$. One challenge in the use of amyloid imaging in early identification of individuals at risk for cognitive impairment and $\mathrm{AD}$ is that as many as $10 \%-30 \%$ of individuals who are clinically healthy on cognitive testing show amyloid deposition in imaging (3) and postmortem studies $(7,8)$.

Evaluation of neuronal activity, using ${ }^{15} \mathrm{O}-\mathrm{H}_{2} \mathrm{O}$, in conjunction with imaging of amyloid deposition, might help clarify the significance of amyloid deposition in older adults without dementia. In view of the suggestion by Buckner et al. (9) that default brain activity in young adulthood may affect amyloid deposition later in life, in this study we evaluated changes in resting-state regional cerebral blood flow (rCBF) that occur during the decade before measurement of amyloid deposition in older individuals without dementia. Such examination is important not only for improved understanding of the longitudinal pathophysiologic relationship between $\mathrm{rCBF}$ and amyloid deposition but also because of potential clinical implications, as joint analysis of $\mathrm{rCBF}$ and ${ }^{11} \mathrm{C}$-PIB data may provide more diagnostic information than a single method alone.

As $\beta$-amyloid is associated with decreased resting $\mathrm{rCBF}$ in animal models (10), we hypothesized that individuals with higher amyloid deposition detected by ${ }^{11} \mathrm{C}$-PIB would exhibit different patterns of longitudinal $\mathrm{rCBF}$ change than those individuals with lower amyloid deposition. We predicted that the longitudinal changes in $\mathrm{rCBF}$ in subjects 
with high ${ }^{11} \mathrm{C}$-PIB retention would involve regions that show decreases in $\mathrm{rCBF}$ in individuals without dementia who eventually progress to AD. These regions would include the anterior and posterior cingulate, insula, middle and superior frontal, and superior temporal regions as well as the caudate nucleus and thalamus (11). In addition, we expected that at least some of the areas of change in longitudinal rCBF would spatially overlap regions of known high ${ }^{11} \mathrm{C}$-PIB retention, as vessel narrowing and subsequent hypoperfusion related to amyloid angiopathy may occur in some regions of ${ }^{11} \mathrm{C}$-PIB retention (12).

\section{MATERIALS AND METHODS}

\section{Study Participants}

Data from 28 participants without dementia (6 with a score of 0.5 on the Clinical Dementia Rating [CDR] (13) Scale) from the neuroimaging substudy (14) of the Baltimore Longitudinal Study of Aging who underwent both $\mathrm{CBF}$ and ${ }^{11} \mathrm{C}$-PIB scans were included in the study. On the basis of the degree of amyloid deposition as determined by the mean cortical distribution volume ratios (DVRs) described later, participants were divided into groups with high ${ }^{11} \mathrm{C}$-PIB retention and low ${ }^{11} \mathrm{C}$-PIB retention. Ten individuals ( 7 men and 3 women; mean age \pm SD, $81.96 \pm$ 4.26 y at ${ }^{11} \mathrm{C}-\mathrm{PIB}$ study) comprised the high- ${ }^{11} \mathrm{C}$-PIB-retention group, and 18 individuals (6 men and 12 women; mean age,
$82.82 \pm 5.11$ y) had low ${ }^{11} \mathrm{C}$-PIB retention. High- and low- ${ }^{11} \mathrm{C}-\mathrm{PIB}-$ retention groups did not differ significantly with respect to age, sex, race, and education (Table 1). All participants underwent neuropsychological evaluation in conjunction with each neuroimaging visit. The CDR Scale, typically informant-based, was administered in conjunction with the ${ }^{11} \mathrm{C}$-PIB imaging study and was previously administered in conjunction with rCBF studies when participants scored 3 or greater on the Blessed-Information-MemoryConcentration (15) test. Cognitive status was determined by consensus diagnosis according to established procedures $(8,16)$. A consensus diagnosis of MCI required progressive memory impairment without functional loss in activities of daily living (2). Informed consent was obtained from each participant before each study. Institutional Review Board approval was obtained for the study.

\section{${ }^{15} \mathrm{O}-\mathrm{H}_{2} \mathrm{O}$ Studies}

${ }^{15} \mathrm{O}-\mathrm{H}_{2} \mathrm{O}$ studies were performed annually for up to 9 assessments over an 8-y follow-up. During each imaging session, a resting PET scan was performed, during which the participants were instructed to keep their eyes open and focused on a computer screen covered by a black cloth. Scans were acquired on a scanner (4096+; GE Healthcare) with 15 slices (axial resolution, 6.5-mm full width at half maximum) and a 9-cm axial field of view. The superiormost portions of the parietal cortex were not evaluated because of the limited axial field of view. Images were obtained for $60 \mathrm{~s}$ once the total radioactivity counts in the brain reached threshold levels. A transmission scan in 2-dimensional mode using

TABLE 1

Demographic and Clinical Characteristics

\begin{tabular}{|c|c|c|c|c|}
\hline Characteristic & Entire group & $\begin{array}{l}\text { High-11 C- } \\
\text { PIB-retention } \\
\text { group }\end{array}$ & $\begin{array}{l}\text { Low- }-{ }^{11} \mathrm{C}- \\
\text { PIB-retention } \\
\text { group }\end{array}$ & $\begin{array}{c}\text { Differences } \\
\text { between high- } \\
\text { and low- }{ }^{11} \text { C-PIB } \\
\text { groups }\end{array}$ \\
\hline No. of participants & 28 & 10 & 18 & \\
\hline CBF studies/participant & $8.5 \pm 0.7(7-9)$ & $8.5 \pm 0.7(7-9)$ & $8.5 \pm 0.7(7-9)$ & NS \\
\hline Age at time of ${ }^{11} \mathrm{C}$-PIB study (y) & $82.5 \pm 4.77$ & $81.96 \pm 4.29$ & $82.83 \pm 5.11$ & NS \\
\hline Age range at time of ${ }^{11} \mathrm{C}-\mathrm{PIB}$ study $(\mathrm{y})$ & $75-92$ & $77-90$ & $75-92$ & \\
\hline $\operatorname{Sex}(M / F)$ & $19 / 9$ & $7 / 3$ & $6 / 12$ & $\mathrm{NS}^{*}$ \\
\hline Handedness (R/L) & $27 / 1$ & $10 / 0$ & $17 / 1$ & $\mathrm{NS}^{*}$ \\
\hline Race (white/African American) & $26 / 2$ & $10 / 0$ & $16 / 2$ & $\mathrm{NS}^{*}$ \\
\hline Education (y) & $17.2 \pm 2.5$ & $17 \pm 2.6$ & $17.3 \pm 2.5$ & NS \\
\hline MMSE at time of ${ }^{11} \mathrm{C}-\mathrm{PIB}$ study ${ }^{\dagger}$ & $28.4 \pm 1.77$ & $27.78 \pm 2.17$ & $28.96 \pm 1.5$ & NS \\
\hline White matter disease burden $\neq$ & $2.21 \pm 1.37$ & $1.7 \pm 0.82$ & $2.5 \pm 1.54$ & NS§ \\
\hline $\begin{array}{l}\text { CDR status (no. with CDR }=0.5 \text { ) } \\
\text { at time of }{ }^{11} \mathrm{C}-\mathrm{PIB} \text { study }\end{array}$ & $6 / 28$ & $5 / 10$ & $1 / 18$ & $P=0.01^{*}$ \\
\hline $\begin{array}{l}\text { Diagnosis of } \mathrm{MCl} \text { at time } \\
\text { of }{ }^{11} \mathrm{C}-\mathrm{PIB} \text { study }\end{array}$ & $1 / 28$ & $1 / 10$ & $0 / 18$ & $\mathrm{NS}^{*}$ \\
\hline Mean cortical DVRף & $1.26 \pm 0.26(1.00-1.80)$ & $1.57 \pm 0.15(1.37-1.80)$ & $1.09+0.10(1.00-1.29)$ & $P<0.001$ \\
\hline
\end{tabular}

*Fisher exact test for independence.

${ }^{\dagger}$ MMSE results from 1 individual $(C D R=0)$ unavailable because of severe hearing impairment.

"White matter ratings used 10-point scale, ranging from 0 (normal) to 9 (thick rind of periventricular white matter disease together with marked subcortical disease), from Cardiovascular Health Study $(37,38)$.

Exact Wilcoxon 2-sample test.

"Mean cortical DVR across orbital frontal, prefrontal superior frontal, lateral temporal, occipital, parietal, anterior cingulate, and posterior cingulate regions.

Results expressed as mean $\pm \mathrm{SD}$, with range in parentheses. Unless otherwise noted, results are based on $t$ tests for independent samples. NS $=$ not significant. 
a ${ }^{68} \mathrm{Ge}$ rotating source was used for attenuation correction. ${ }^{15} \mathrm{O}-$ $\mathrm{H}_{2} \mathrm{O}$ PET studies were not adjusted for partial-volume effects because of increased variance associated with correction of relatively lower-resolution CBF images. A total of $238 \mathrm{CBF}$ scans from 28 participants were available for analysis; $15 \mathrm{CBF}$ scans were not available. The mean \pm SD number of scans per participant was $8.5 \pm 0.7$ (range, 7-9). No significant differences between the proportions of unavailable studies for high- and low- ${ }^{11} \mathrm{C}-\mathrm{PIB}-$ retention groups $\left(\chi^{2} ; P=1.0\right)$ were observed.

\section{${ }^{11} \mathrm{C}-\mathrm{PIB}$ Studies}

Dynamic ${ }^{11} \mathrm{C}$-PIB PET studies were performed on average $10.8 \pm 0.8 \mathrm{y}$ after the first and $2.8 \pm 0.8 \mathrm{y}$ after the last CBF scan as part of the Baltimore Longitudinal Study of Aging neuroimaging study. Studies were performed on a GE Advance scanner in 3-dimensional mode, and 37 time frames $(90 \mathrm{~min}$ ) were obtained at rest. The PET scanning started immediately after an intravenous bolus injection of $529.1 \pm 37 \mathrm{MBq}(14.3 \pm 1 \mathrm{mCi})$ of ${ }^{11} \mathrm{C}$-PIB with a specific activity of $152.81 \pm 55.5 \mathrm{GBq} / \mu \mathrm{mol}$ $(4.13 \pm 1.5 \mathrm{Ci}) / \mu \mathrm{mol}$ (range, 36.26-249.01 GBq/ $\mu \mathrm{mol}[0.98-6.73$ $\mathrm{Ci} / \mu \mathrm{mol}])$. Participants were fitted with a thermoplastic mask for PET to minimize motion during scanning. Transmission scans in 2-dimensional mode were used for attenuation correction of the emission scans. Dynamic images were reconstructed using filtered backprojection with a ramp filter (image size, $128 \times 128$; pixel size, $2 \times 2 \mathrm{~mm}$; slice thickness, $4.25 \mathrm{~mm}$ ), yielding a spatial resolution of about $4.50-\mathrm{mm}$ full width at half maximum at the center of the field of view. We did not perform partial-volume correction on the ${ }^{11} \mathrm{C}$-PIB images, but the partial-volume effect was minimized by excluding edges of tissue in definition of volumes of interest. In view of the high noise level of voxel-based kinetics, the benefits of partial-volume correction of ${ }^{11} \mathrm{C}-\mathrm{PIB}$ images remain uncertain (17).

\section{MRI-Based Region-of-Interest (ROI) Definition}

Spoiled gradient-recalled MRI scans (124 slices; image matrix, $256 \times 256$; pixel size, $0.93 \times 0.93 \mathrm{~mm}$; slice thickness, $1.5 \mathrm{~mm}$ ) were coregistered to the mean of the first 20-min dynamic PET images for each participant using the mutual information method in the Statistical Parametric Mapping software (SPM2; Wellcome Department of Cognitive Neurology). In addition to the cerebellum, which was used as a reference region, 15 ROIs (caudate, putamen, thalamus, lateral temporal, mesial temporal, orbital frontal, prefrontal, occipital, superior frontal, parietal, anterior cingulate, posterior cingulate, pons, midbrain, and white matter) were manually drawn on the coregistered MR images (18).

\section{Quantification of DVRs and Definition of High- and Low- ${ }^{11}$ C-PIB-Retention Groups}

The DVRs of ROIs were estimated by simultaneous fitting of a reference-tissue model to the 15 measured ROI time-activity curves (19). In addition, DVR images were generated for voxelwise analysis $(17,19)$. The mean cortical DVR was calculated by averaging DVR values from orbitofrontal, prefrontal, superior frontal, parietal, lateral temporal, occipital, and anterior and posterior cingulate regions. The mean cortical DVR was used to form groups rather than used as a continuous variable because of the possibility that associations with $\mathrm{rCBF}$ change would not be uniform across the range of cortical DVR values. For example, no relationships may be evident in individuals with low ${ }^{11} \mathrm{C}$-PIB values. To separate individuals into 2 groups, we used the 2-group $\mathrm{K}$-mean cluster analysis in SAS 9.1 (SAS Institute, Inc.).

\section{SPM Analysis of CBF Scans}

Using SPM2, PET CBF scans were realigned, spatially normalized into standard stereotactic space, and smoothed using a gaussian filter of 12,12 , and $12 \mathrm{~mm}$ in the $x, y$, and $z$ planes, respectively. To control for variability in global flow, $\mathrm{rCBF}$ values at each voxel were ratio-adjusted to the mean global flow of 50 $\mathrm{mL} / 100 \mathrm{~g} / \mathrm{min}$ for each image. The image data were analyzed using voxel-by-voxel comparisons to assess differences in linear rCBF changes between the high- and low- ${ }^{11} \mathrm{C}-\mathrm{PIB}$ groups over time across all data points. Group $x$ time interactions of linear changes in $\mathrm{rCBF}$ were computed, covarying for sex and the time between the last $\mathrm{rCBF}$ study and the ${ }^{11} \mathrm{C}$-PIB study. Significant effects for each contrast were based on the magnitude $(P \leq 0.001)$ and spatial extent $\left(>200 \mathrm{~mm}^{3}\right)$ of differences between groups.

\section{Spatial Distribution of Differences in rCBF and ${ }^{11} \mathrm{C}$-PIB for High- Versus Low-11C-PIB Groups}

Using SPM2, ${ }^{11} \mathrm{C}$-PIB parametric DVR images were spatially normalized and smoothed using a gaussian filter of 8,8 , and $8 \mathrm{~mm}$ in the $x, y$, and $z$ planes. A 2-group $t$ test was used to assess differences between the high- and low- ${ }^{11} \mathrm{C}$-PIB-retention groups. Significant effects were determined on the basis of magnitude $(P \leq 0.001)$ and spatial extent $\left(>200 \mathrm{~mm}^{3}\right)$. For graphical illustration, significant differences in longitudinal rCBF change between the high- and low- ${ }^{11} \mathrm{C}$-PIB-retention groups were superimposed on $t$ maps of differences in amyloid deposition between the high- and low- ${ }^{11} \mathrm{C}$-PIB groups using the Amide software (version 3) (20). To determine whether regions showing significant group differences in $\mathrm{rCBF}$ change overlap with those showing differences in amyloid deposition, a restricted search analysis was performed limited to regions showing significant group differences in rCBF (mask threshold, $P=0.05$ ).

\section{RESULTS}

\section{Study Participants}

High- and low- ${ }^{11} \mathrm{C}-\mathrm{PIB}-$ retention groups were similar in age and other demographic characteristics and did not differ significantly in white matter signal abnormalities on MRI. Compared with the low- ${ }^{11} \mathrm{C}$-PIB-retention group, the high- ${ }^{11} \mathrm{C}-\mathrm{PIB}$ group showed a nonsignificant trend for lower scores on the Mini-Mental Status Examination (MMSE). In addition, mean CDR scores were higher in the high- ${ }^{11} \mathrm{C}$-PIBretention group (Table 1) than those in the low- ${ }^{11} \mathrm{C}-\mathrm{PIB}$ group. At the time of the ${ }^{11} \mathrm{C}$-PIB study, the high- ${ }^{11} \mathrm{C}$-PIBretention group included only 1 individual $(\mathrm{CDR}=0.5)$ who met consensus criteria for MCI. The remainder of the high- ${ }^{11} \mathrm{C}$-PIB group included 4 individuals with a CDR of 0.5 who did not yet meet consensus criteria for MCI and 5 individuals with a CDR of 0 . Four of the 5 individuals with a CDR of 0.5 received their initial rating of 0.5 during imaging visits before the ${ }^{11} \mathrm{C}$-PIB PET study, but none of the 4 progressed to a CDR greater than 0.5 during follow-up. During the $8 \mathrm{y}$ of $\mathrm{CBF}$ imaging, none of the participants in either group developed central nervous system disease (stroke, epilepsy, brain tumor, Parkinson's disease) or severe cardiac disease (myocardial infarction, coronary artery disease requiring angioplasty or bypass surgery). 


\section{Cluster Analysis of Mean Cortical DVR}

To separate individuals into 2 groups, we used 2-group $\mathrm{K}$-mean cluster analysis and used a cubic clustering criterion to test for uniformity within the data. This analysis identified 2 clusters separated at approximately 1.3 DVR, characterized by a cubic clustering criterion of 0.547 , which indicates that they represent potential clusters (Fig. 1). On the basis of the cluster analysis, 10 participants were assigned to the high- ${ }^{11} \mathrm{C}$-PIB-retention group and 18 participants were assigned to the low- ${ }^{11} \mathrm{C}-\mathrm{PIB}-$ retention group. Significantly more participants in the high- ${ }^{11} \mathrm{C}$-PIB-retention group than in the low- ${ }^{11} \mathrm{C}-\mathrm{PIB}-$ retention group $(P=0.0126)$ had a CDR of 0.5 at the time of the ${ }^{11} \mathrm{C}-\mathrm{PIB}$ study (Table 1). Only 1 participant in the low- ${ }^{11} \mathrm{C}$-PIB-retention group had a CDR score of 0.5 , with a CDR sum of the boxes equal to 0.5 . Individuals in the high- ${ }^{11} \mathrm{C}$-PIB-retention group with a CDR of 0.5 had very mild cognitive impairment (mean CDR sum of boxes, 1.5 [ \pm 0.5$]$; maximum sum of boxes, 2).

\section{Longitudinal Changes in High- and Low- ${ }^{11} \mathrm{C}-\mathrm{PIB}-$ Retention Groups}

Longitudinal increases and decreases in rCBF differed significantly between high- and low- ${ }^{11} \mathrm{C}-\mathrm{PIB}-$ retention groups $\left(P \leq 0.001 ;>200 \mathrm{~mm}^{3}\right.$ spatial extent). Compared with the low- ${ }^{11} \mathrm{C}$-PIB group, greater increases over time in rCBF in the high- ${ }^{11} \mathrm{C}$-PIB group were seen in the left medial frontal (Brodmann's area [BA] 10) and left inferior frontal gyri (BA 45/46), right precuneus (BA 7), left inferior parietal lobule (BA 40), and left postcentral gyrus (BA 43). Greater decreases in rCBF over time in the high- ${ }^{11} \mathrm{C}$-PIB group than in the low- ${ }^{11} \mathrm{C}$-PIB group were found in the right anterior to middle cingulate (BA 32/24), right supramarginal gyrus (BA 40), left thalamus, and midbrain bilaterally (Table 2).

Voxel-based differences in amyloid deposition between the high- and low- ${ }^{11} \mathrm{C}-\mathrm{PIB}-$ retention groups are shown in Figure 2 in the lower row. The pattern of voxel-based differences in ${ }^{11} \mathrm{C}$-PIB retention between the groups is very similar to a map of ${ }^{11} \mathrm{C}$-PIB retention in a typical AD case.
Superimposed on the voxel-based differences in ${ }^{11} \mathrm{C}-\mathrm{PIB}$ retention between the groups are regions of significant differences in longitudinal rCBF change between the groups. As confirmed by restricted search analysis, all regions, except brain stem and inferior thalamus, that show significant differences in longitudinal rCBF change between highand low- ${ }^{11} \mathrm{C}-\mathrm{PIB}$ groups overlap regions of greater amyloid retention in the high- ${ }^{11} \mathrm{C}-\mathrm{PIB}$ group.

\section{DISCUSSION}

This evaluation of older adults without dementia demonstrates regionally specific differences in longitudinal rCBF changes over time between individuals with and without amyloid deposition. In the years preceding measurement of amyloid deposition, both greater increases and greater decreases over time are observed in specific brain regions when individuals without dementia with high cortical ${ }^{11} \mathrm{C}$-PIB retention are compared with individuals with low ${ }^{11} \mathrm{C}$-PIB retention. The spatial distribution of $\mathrm{rCBF}$ changes in the high- ${ }^{11} \mathrm{C}$-PIB group occurs primarily in areas with known amyloid deposition; however, not all areas that have been documented previously to have high ${ }^{11} \mathrm{C}$-PIB retention show longitudinal $\mathrm{rCBF}$ changes. Differences in longitudinal rCBF change between the high- and low- ${ }^{11} \mathrm{C}$-PIB-retention groups are seen in some structures that have altered $\mathrm{rCBF}$ in individuals with MCI who progress to $\mathrm{AD}(11,21)$. Unlike these cross-sectional imaging studies, the high- ${ }^{11} \mathrm{C}-\mathrm{PIB}-$ retention group in our study is composed of a mix of healthy elderly and individuals with a CDR of 0.5 , of whom only 1 has a consensus diagnosis of MCI. These differences in sample characteristics may account for differences between our findings and those of studies of individuals with $\mathrm{MCI}$ who progress to $\mathrm{AD}$.

Greater declines in $\mathrm{rCBF}$ over time in the high- than in the low- ${ }^{11} \mathrm{C}-\mathrm{PIB}-$ retention group were found in the anterior cingulate gyrus extending to the right middle cingulate gyrus, the supramarginal gyrus, the thalamus, and the midbrain. Decreased rCBF has been previously reported

TABLE 2

Differences in Longitudinal rCBF Changes in High- Versus Low- ${ }^{11} \mathrm{C}-\mathrm{PIB}-$ Retention Groups

\begin{tabular}{|c|c|c|c|c|c|c|c|}
\hline \multirow[b]{2}{*}{ Region } & \multirow[b]{2}{*}{ Brodmann's area } & \multirow[b]{2}{*}{ Side } & \multicolumn{3}{|c|}{ Coordinate } & \multirow[b]{2}{*}{$t$ value } & \multirow[b]{2}{*}{$P$ (uncorrected) } \\
\hline & & & $x$ & $y$ & $z$ & & \\
\hline \multicolumn{8}{|c|}{ Greater linear increases in rCBF } \\
\hline Precuneus & 7 & $\mathrm{R}$ & 6 & -48 & 44 & 3.55 & $<0.001$ \\
\hline Inferior parietal lobule & 40 & $\mathrm{~L}$ & -58 & -22 & 28 & 3.25 & 0.001 \\
\hline Postcentral gyrus & 43 & $\mathrm{~L}$ & -46 & -12 & 22 & 3.58 & $<0.001$ \\
\hline Medial frontal gyrus & 10 & $\mathrm{~L}$ & -8 & 50 & 14 & 3.60 & $<0.001$ \\
\hline Inferior frontal gyrus & $45 / 46$ & $\mathrm{~L}$ & -32 & 28 & 12 & 4.41 & $<0.001$ \\
\hline \multicolumn{8}{|c|}{ Greater linear decreases in rCBF } \\
\hline Cingulate gyrus & $32 / 24$ & $\mathrm{R}$ & 16 & 22 & 28 & 4.51 & $<0.001$ \\
\hline Supramarginal gyrus & 40 & $\mathrm{R}$ & 48 & -52 & 34 & 3.01 & 0.001 \\
\hline Thalamus & & $\mathrm{L}$ & -2 & -14 & 14 & 3.74 & $<0.001$ \\
\hline Midbrain & & $\mathrm{R}$ & 4 & -24 & -8 & 3.18 & 0.001 \\
\hline Midbrain & & $\mathrm{L}$ & -6 & -18 & -2 & 3.12 & 0.001 \\
\hline
\end{tabular}




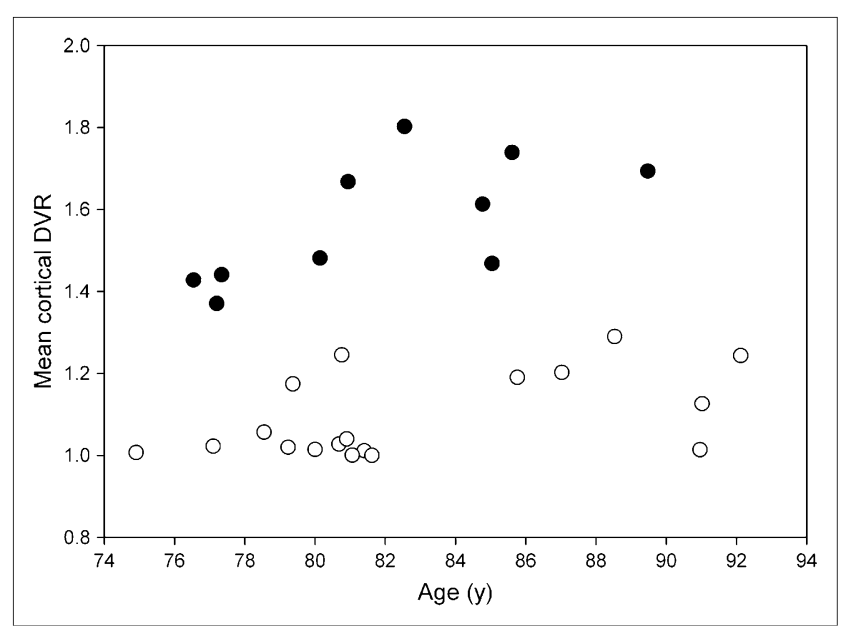

FIGURE 1. Scatterplot of association between age and mean cortical DVR. With 2-group K-mean cluster analysis, 2 clusters of individuals were identified: one with higher ${ }^{11} \mathrm{C}$-PIB retention and another with lower ${ }^{11} \mathrm{C}$-PIB retention, as determined by mean cortical DVR.

in the anterior cingulate gyrus on SPECT of individuals who converted to $\mathrm{AD}$ (22), and deficits in executive function, in which the anterior cingulate has been reported to play a role, are among those exhibited early in the course of $\mathrm{AD}$ (23). In addition to the greater longitudinal decrease in the anterior cingulate for the high- ${ }^{11} \mathrm{C}$-PIB-retention group, we also observed greater decreases over time for the high- ${ }^{11} \mathrm{C}$-PIB group in the supramarginal gyrus and thalamus. CBF decreases in the supramarginal gyrus have been observed previously in cross-sectional studies comparing individuals with $\mathrm{AD}$ with controls $(24,25)$ and in longitudinal follow-up of individuals with AD (25). SPECT studies have also shown early involvement of the thalamus in $\mathrm{AD}$ (22). We also found greater longitudinal declines in midbrain $\mathrm{rCBF}$ in the high- ${ }^{11} \mathrm{C}-\mathrm{PIB}$ group, indicating greater decreases in neural activity in this region. We did not observe significant group differences in longitudinal rCBF changes for the posterior cingulate gyrus, an area showing early decreases in $\operatorname{rCBF}(22,25)$ and glucose metabolism (26) as well as increased amyloid deposition $(27,28)$ in individuals diagnosed with MCI and AD.

Greater decreases in longitudinal $\mathrm{rCBF}$ in those with high amyloid deposition may represent the inability to further offset neuronal insult or neuronal death, a process that is also associated with decreased ${ }^{18} \mathrm{~F}$-FDG activity in areas with high ${ }^{11} \mathrm{C}$-PIB deposition $(1,28,29)$. In addition to focal decreases in neural activity, several other mechanisms either alone or in combination may explain decreases in CBF. These include compromise of the lumina of small vessels due to amyloid deposition itself or vasoconstrictive properties of endothelin-1, a molecule formed during interaction of $A \beta$ with the receptor for advanced glycation end products (30); decreased synaptic integration (31); decreased choline acetyltransferase activity as an individual progresses toward AD (32); degeneration of indirect projections from the basal forebrain to cerebral microcirculation (33); and cell death due to amyloid toxicity (34).

We also found some regions that showed greater longitudinal increases in $\mathrm{rCBF}$ in those with higher amyloid load, compared with those with low amyloid load. These regions included inferior and medial frontal, postcentral, and inferior parietal lobule regions and the precuneus. All these regions with greater longitudinal $\mathrm{rCBF}$ increases also showed greater amyloid deposition in the high- ${ }^{11} \mathrm{C}-\mathrm{PIB}-$ retention group in a voxel-based analysis. In one ${ }^{11} \mathrm{C}$-PIB PET study of individuals without dementia, the precuneus was reported to be the first region showing significant amyloid deposition (3). In addition to precuneus and posterior cingulate, the frontal regions have also shown pronounced ${ }^{11} \mathrm{C}$-PIB retention in prior studies $(1,4$ $6,27,28)$. Notably, these neocortical regions also demonstrate early amyloid deposition in pathologic studies $(7,8)$.

Although decline in neuronal function has been extensively documented, especially once an individual has been diagnosed with $\mathrm{AD}$, accumulating evidence indicates potential increases in regional brain activity in the very early stages of cognitive impairment. Relative increases in $\mathrm{rCBF}$

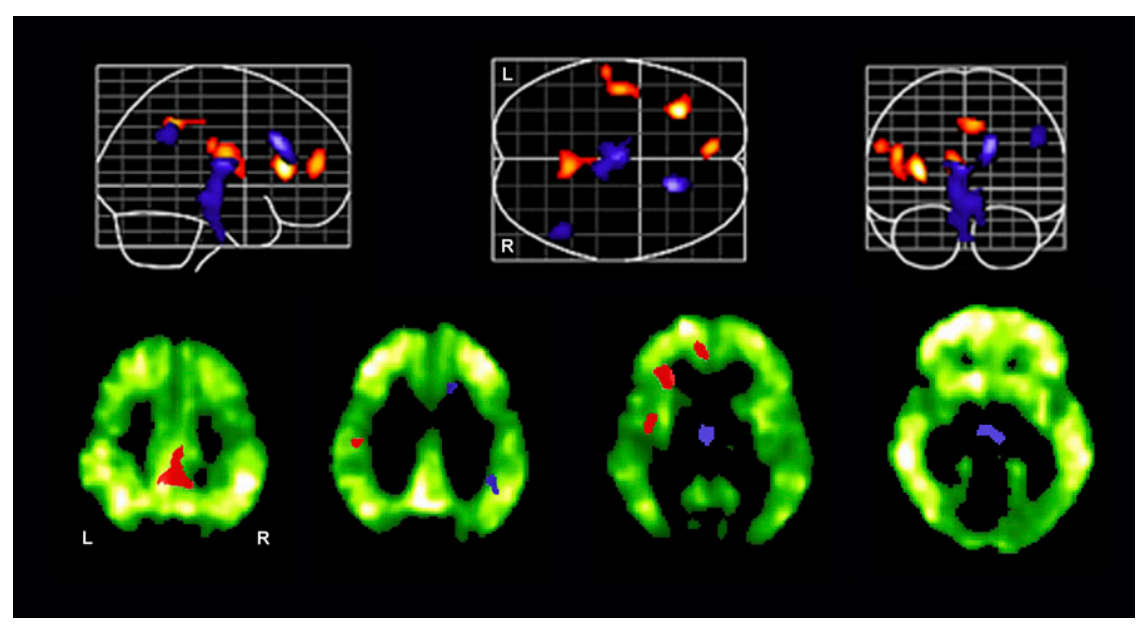

FIGURE 2. Longitudinal rCBF increases (red) and decreases (blue) over 8-y interval in group with high amyloid deposition, compared with group with low amyloid deposition. In lower row, differences in longitudinal rCBF changes are overlaid on selected axial images showing voxelbased differences in amyloid deposition between high- and low- ${ }^{11} \mathrm{C}-\mathrm{PIB}$ groups. 
have been found in frontal regions in individuals who later progress to dementia, compared with controls and individuals with MCI who remain stable (21). Functional MRI studies of individuals with MCI also indicate initial increases in neuronal function early in the disease process (35). Moreover, neuropathologic studies of cognitively intact individuals whose postmortem findings are consistent with $\mathrm{AD}$ show hypertrophy of neuronal nuclei, nucleoli, and cell bodies in several brain regions, as compared with controls (36). These changes, which may be a marker of the resistance of the brain to the effects of amyloid deposition, would likely be associated with increased $\mathrm{rCBF}$ in view of increased metabolic demands. Although the concurrent relationship between $\mathrm{rCBF}$ and amyloid deposition has not yet, to our knowledge, been reported, our findings of greater longitudinal increase in $\mathrm{rCBF}$ in some brain regions of individuals with increased amyloid load is consistent with these other observations of increased neuronal activity in individuals with no or early MCI.

Although the specific mechanisms related to these longitudinal changes in rCBF remain unclear, either amyloid deposition itself or one of the pathophysiologic processes associated with amyloid deposition may play a role in the observed changes. One possible explanation for the pattern of greater longitudinal increases and decreases in $\mathrm{rCBF}$ in association with amyloid deposition may be that greater decreases in $\mathrm{rCBF}$ across time represent a response to neuronal insult that subsequently leads to neuronal death, whereas greater longitudinal increases in $\mathrm{rCBF}$ represent an attempt to preserve neuronal function despite an increase in amyloid load. These increases in $\mathrm{rCBF}$, possibly representing neuronal plasticity changes, may play a role in the maintenance of cognitive function until such processes are overcome by increasing pathophysiology.

\section{CONCLUSION}

We demonstrate that the pattern of longitudinal rCBF changes in those with high ${ }^{11} \mathrm{C}-\mathrm{PIB}$ retention differs from those with low ${ }^{11} \mathrm{C}$-PIB retention. In this group of older adults without dementia, those with high ${ }^{11} \mathrm{C}$-PIB deposition show a decline in $\mathrm{rCBF}$ over the previous years, probably reflecting decrements in neuronal function. However, in the same group, there is also a greater increase in $\mathrm{rCBF}$ over time seen in other areas, suggesting that compensatory mechanisms aimed at preserving brain function are invoked in the setting of amyloid deposition. The spatial distribution of these changes corresponds to regions typically showing high amyloid deposition; however, not all areas of known amyloid deposition show changes in rCBF. Concurrent evaluation of longitudinal changes in rCBF and amyloid deposition with changes in cognitive status will be required to investigate in detail the interplay between CBF and amyloid deposition and their possible clinical implications. Further development, refinement, and application of different physiologic and molecular probes, in concert with longitudinal and perhaps more focused and refined clinical observations, will bring us closer to understanding the pathophysiology of $\mathrm{MCI}$ and $\mathrm{AD}$ and may aid in determining which individuals at risk for $\mathrm{AD}$ are most likely to progress to disease.

\section{ACKNOWLEDGMENTS}

We thank the staff of the PET facility at Johns Hopkins University and the neuroimaging staff of the National Institute on Aging (NIA) for their assistance. This research was supported by the Intramural Research Program of the National Institutes of Health (NIH), by the NIA, and by NIH grants N01-AG-3-2124 and K24 DA00412. GE Healthcare holds a license agreement with the University of Pittsburgh based on the PIB technology described in this manuscript. Drs. Klunk and Mathis are co-inventors of PIB and, as such, have a financial interest in this license agreement.

\section{REFERENCES}

1. Klunk WE, Engler H, Nordberg A, et al. Imaging brain amyloid in Alzheimer's disease with Pittsburgh compound-B. Ann Neurol. 2004;55:306-319.

2. Petersen RC, Morris JC. Mild cognitive impairment as a clinical entity and treatment target. Arch Neurol. 2005;62:1160-1163.

3. Mintun MA, Larossa GN, Sheline YI, et al. $\left[{ }^{11} \mathrm{C}\right] \mathrm{PIB}$ in a nondemented population: potential antecedent marker of Alzheimer disease. Neurology. 2006;67:446-452.

4. Rowe CC, $\mathrm{Ng} \mathrm{S}$, Ackermann U, et al. Imaging $\beta$-amyloid burden in aging and dementia. Neurology. 2007;68:1718-1725.

5. Kemppainen NM, Aalto S, Wilson IA, et al. PET amyloid ligand $\left[{ }^{11} \mathrm{C}\right] \mathrm{PIB}$ uptake is increased in mild cognitive impairment. Neurology. 2007;68:16031606

6. Forsberg A, Engler H, Almkvist O, et al. PET imaging of amyloid deposition in patients with mild cognitive impairment. Neurobiol Aging. May 10, 2007 [Epub ahead of print].

7. Galvin JE, Powlishta KK, Wilkins K, et al. Predictors of preclinical Alzheimer disease and dementia: a clinicopathologic study. Arch Neurol. 2005;62:758765.

8. Driscoll I, Resnick SM, Troncoso JC, An Y, O’Brien R, Zonderman AB. Impact of Alzheimer's pathology on cognitive trajectories in nondemented elderly. Ann Neurol. 2006;60:688-695.

9. Buckner RL, Snyder AZ, Shannon BJ, et al. Molecular, structural, and functional characterization of Alzheimer's disease: evidence for a relationship between default activity, amyloid, and memory. J Neurosci. 2005;25:7709-7717.

10. Niwa K, Carlson GA, Iadecola C. Exogenous A $\beta 1-40$ reproduces cerebrovascular alterations resulting from amyloid precursor protein overexpression in mice. J Cereb Blood Flow Metab. 2000;20:1659-1668.

11. Johnson KA, Moran EK, Becker JA, Blacker D, Fischman AJ, Albert MS. Single photon emission computed tomography perfusion differences in mild cognitive impairment. J Neurol Neurosurg Psychiatry. 2007;78:240-247.

12. Bacskai BJ, Frosch MP, Freeman SH, et al. Molecular imaging with Pittsburgh compound B confirmed at autopsy: a case report. Arch Neurol. 2007;64:431-434.

13. Morris JC. The Clinical Dementia Rating (CDR): current version and scoring rules. Neurology. 1993;43:2412-2414.

14. Resnick SM, Goldszal AF, Davatzikos C, et al. One-year age changes in MRI brain volumes in older adults. Cereb Cortex. 2000;10:464-472.

15. Blessed G, Tomlinson BE, Roth $M$. The association between quantitative measures of dementia and of senile change in the cerebral grey matter of elderly subjects. Br J Psychiatry. 1968;114:797-811.

16. Kawas C, Gray S, Brookmeyer R, Fozard J, Zonderman A. Age-specific incidence rates of Alzheimer's disease: the Baltimore Longitudinal Study of Aging. Neurology. 2000;54:2072-2077.

17. Zhou Y, Endres CJ, Brasic JR, Huang SC, Wong DF. Linear regression with spatial constraint to generate parametric images of ligand-receptor dynamic PET studies with a simplified reference tissue model. Neuroimage. 2003;18: 975-989. 
18. Price JC, Klunk WE, Lopresti BJ, et al. Kinetic modeling of amyloid binding in humans using PET imaging and Pittsburgh Compound-B. J Cereb Blood Flow Metab. 2005;25:1528-1547.

19. Zhou Y, Resnick SM, Ye W, et al. Using a reference tissue model with spatial constraint to quantify $\left[{ }^{11} \mathrm{C}\right]$ Pittsburgh compound B PET for early diagnosis of Alzheimer's disease. Neuroimage. 2007;36:298-312.

20. Loening AM, Gambhir SS. AMIDE: a free software tool for multimodality medical image analysis. Mol Imaging. 2003;2:131-137.

21. Huang C, Wahlund LO, Almkvist O, et al. Voxel- and VOI-based analysis of SPECT CBF in relation to clinical and psychological heterogeneity of mild cognitive impairment. Neuroimage. 2003;19:1137-1144.

22. Johnson KA, Jones K, Holman BL, et al. Preclinical prediction of Alzheimer's disease using SPECT. Neurology. 1998;50:1563-1571.

23. Perry RJ, Hodges JR. Attention and executive deficits in Alzheimer's disease: a critical review. Brain. 1999;122:383-404.

24. Scarmeas N, Habeck CG, Zarahn E, et al. Covariance PET patterns in early Alzheimer's disease and subjects with cognitive impairment but no dementia: utility in group discrimination and correlations with functional performance. Neuroimage. 2004;23:35-45.

25. Kogure D, Matsuda H, Ohnishi T, et al. Longitudinal evaluation of early Alzheimer's disease using brain perfusion SPECT. J Nucl Med. 2000;41:1155-1162.

26. Minoshima S, Giordani B, Berent S, Frey KA, Foster NL, Kuhl DE. Metabolic reduction in the posterior cingulate cortex in very early Alzheimer's disease. Ann Neurol. 1997;42:85-94.

27. Kemppainen NM, Aalto S, Wilson IA, et al. Voxel-based analysis of PET amyloid ligand $\left[{ }^{11} \mathrm{C}\right] \mathrm{PIB}$ uptake in Alzheimer disease. Neurology. 2006;67:1575-1580.

28. Edison P, Archer HA, Hinz R, et al. Amyloid, hypometabolism, and cognition in Alzheimer disease: an $\left[{ }^{11} \mathrm{C}\right] \mathrm{PIB}$ and $\left[{ }^{18} \mathrm{~F}\right] \mathrm{FDG}$ PET study. Neurology. 2007;68: 501-508.
29. Engler H, Forsberg A, Almkvist O, et al. Two-year follow-up of amyloid deposition in patients with Alzheimer's disease. Brain. July 19, 2006 [Epub ahead of print].

30. Deane R, Du Yan S, Submamaryan RK, et al. RAGE mediates amyloid- $\beta$ peptide transport across the blood-brain barrier and accumulation in brain. Nat Med. 2003;9:907-913.

31. Stern EA, Bacskai BJ, Hickey GA, Attenello FJ, Lombardo JA, Hyman BT. Cortical synaptic integration in vivo is disrupted by amyloid-beta plaques. J Neurosci. 2004;24:4535-4540.

32. DeKosky ST, Ikonomovic MD, Styren SD, et al. Upregulation of choline acetyltransferase activity in hippocampus and frontal cortex of elderly subjects with mild cognitive impairment. Ann Neurol. 2002;51:145-155.

33. Tong XK, Hamel E. Regional cholinergic denervation of cortical microvessels and nitric oxide synthase-containing neurons in Alzheimer's disease. Neuroscience. 1999;92:163-175.

34. Nakamura S, Murayama N, Noshita T, Annoura H, Ohno T. Progressive brain dysfunction following intracerebroventricular infusion of beta ${ }_{1-42}$-amyloid peptide. Brain Res. 2001;912:128-136.

35. Dickerson BC, Sperling RA. Functional abnormalities of the medial temporal lobe memory system in mild cognitive impairment and Alzheimer's disease: insights from functional MRI studies. Neuropsychologia. 2008;46:1624-1635.

36. Iacono D, O'Brien R, Resnick SM, et al. Neuronal hypertrophy in asymptomatic Alzheimer's disease. J Neuropathol Exp Neurol. 2008;67:578-589.

37. Manolio TA, Kronmal RA, Burke GL, et al. Magnetic resonance abnormalities and cardiovascular disease in older adults. The Cardiovascular Health Study. Stroke. 1994;25:318-327.

38. Kraut MA, Beason-Held LL, Elkins WD, Resnick SM. The impact of magnetic resonance imaging-detected white matter hyperintensities on longitudinal changes in regional cerebral blood flow. J Cereb Blood Flow Metab. 2008;28: 190-197. 